\title{
Adherence to secondary prevention therapies in acute coronary syndrome
}

\section{Jay B Thakkar \\ MBBS MD FRACP PhD Student $^{1}$ \\ Clara K Chow MBBS, FRACP, PhD Head, $^{2}$ and Program Director ${ }^{3}$ \\ 1Department of Cardiology, Westmead Hospital, Sydney, NSW. \\ 2 Cardiac Program, \\ The George Institute for Global Health, University of Sydney, Sydney, NSW. \\ 3 Community Based Cardiac Services, Westmead Hospital, Sydney, NSW. \\ drjaythakkar@ yahoo.com.au}

doi: 10.5694/mjal4.01157
"Drugs don't work in patients who don't take them."

- C Everett Koop

. espite the overwhelming evidence of the effectiveness of secondary prevention therapies, ${ }^{1,2}$ surveys locally and overseas indicate poor uptake of medical treatments and lifestyle recommendations after an acute coronary syndrome (ACS), 3,4 and a concerning lack of recognition of this problem by clinicians. ${ }^{3-5}$ In one cross-sectional survey of Australian general practices, only about a half of patients with known coronary heart disease were taking recommended treatments. ${ }^{5}$ This is similar to findings from other high-income countries, and the situation is much worse in low- and middle-income countries. ${ }^{6}$ Adherence to lifestyle recommendations is also poor, with only about a third of patients adherent to lifestyle recommendations on diet, exercise and smoking 6 months after their ACS.?

The World Health Organization defines adherence as "the extent to which a person's behaviour — taking medication, following a diet, and/or executing lifestyle changes, corresponds with agreed recommendations from a health care provider". 8 The terms compliance and adherence are conceptually similar. However, an important difference is that adherence better reflects active involvement of the patient and a therapeutic alliance with the physician, whereas compliance implies passive patient obedience., ${ }^{9,10}$ Poor adherence may be conscious or unconscious, and includes patients missing doses, missing days, taking drug "holidays", and forgetting to renew their prescriptions. Adherence also encompasses persistence - the continued taking of medications for the intended course of therapy.

Poor adherence results from complex interplay of multiple factors (Box 1). At the individual level, this ranges from physical disability and mental health to patients' perceptions of their illness, health literacy and social context. ${ }^{11}$ Physicians contribute to the problem by prescribing complex therapies, failing to identify non-adherence and failing to identify side effects. There is growing evidence that many trials underestimate the severity of side effects. ${ }^{12,13}$ Also, clinicians may fail to recognise nonadherence in as many as half of their patients identified as non-adherent based on pharmacy claims data. ${ }^{14}$

While an ACS event would be expected to motivate a person to change behaviour, patients stop taking their medications as early as a few weeks after discharge, and non-adherence rates increase with time. ${ }^{15,16}$ According to one study of 1521 patients with acute myocardial infarction (AMI), at 1 month after AMI, 18\% reported discontinuing at least one of the three major drug classes (aspirin, $\beta$-blocker or statin). ${ }^{15}$

Not surprisingly, poor adherence is associated with worse outcomes. In one population-based longitudinal observational study of more than 30000 AMI survivors, poor adherence to statins in the first year after AMI was associated with a $25 \%$ higher risk of mortality. ${ }^{17}$ Premature

\section{Sunnากเท \\ Despite overwhelming evidence of the effectiveness of secondary prevention therapies, surveys indicate poor adherence to medical treatments and lifestyle recommendations after an acute coronary syndrome. \\ - The term adherence is preferred over compliance, as the former suggests a therapeutic alliance, whereas the latter reflects passive patient obedience. \\ - Poor adherence results from a complex interplay of multiple factors at patient, practitioner and system levels. \\ Poor adherence among patients with stable coronary artery disease is associated with increased risk of cardiovascular admissions (10\%-40\%), coronary interventions (10\%-30\%) and cardiovascular mortality (50\%-80\%).}

Improving adherence is a complex process. A range of interventions that target modifiable factors influencing adherence have been explored, but there are no guidelines to guide the choice, and multidisciplinary efforts may be needed.

Future research in the area should focus on comparative efficacy of interventions to enhance adherence.

discontinuation of thienopyridines (eg, clopidogrel) within a month after an AMI treated with drug-eluting stents was associated with increased mortality during the next 11 months $(7.5 \%$ v $0.7 \% ; P<0.001)$ and increased hospitalisation (23\% v 14\%; hazard ratio, 1.5$).{ }^{18}$ Similarly, among patients with stable coronary disease, non-adherence to angiotensin-converting enzyme (ACE) inhibitors, $\beta$-blockers and/or statins, identified in $25 \%$ of patients, were each associated with an increased relative risk of cardiovascular re-admissions (range, $10 \%-40 \%$ ), coronary interventions (range, 10\%-30\%) and cardiovascular mortality (range, $50 \%-80 \%$ ). ${ }^{19}$ Good adherence is associated with improved outcomes. In analyses of the CRUSADE ACS registry, every $10 \%$ increase in the overall composite guideline adherence was associated with a $10 \%$ decrease in the likelihood of inhospital mortality. ${ }^{20}$ Better outcomes with adherence may be due to a "healthy adherer" effect. In clinical trials, even patients more adherent to placebo have better outcomes. ${ }^{7,21}$

\section{Detection of non-adherence}

Measuring non-adherence is challenging. Even in the research setting, there is no gold standard tool. For some types of drugs, a direct technique can be applied; for example, measuring levels of the drug or its metabolite in blood or urine, or the effect of the drug on a known biochemical measure (eg, cholesterol levels). Other methods used in trials include pharmacy refill records and pill counts, but these do not account for "pill dumping" and pattern of intake (erratic timing). Several clinical trials use the MEMS (Medication Event Monitoring System), which is a microprocessor attached to a bottle to record 


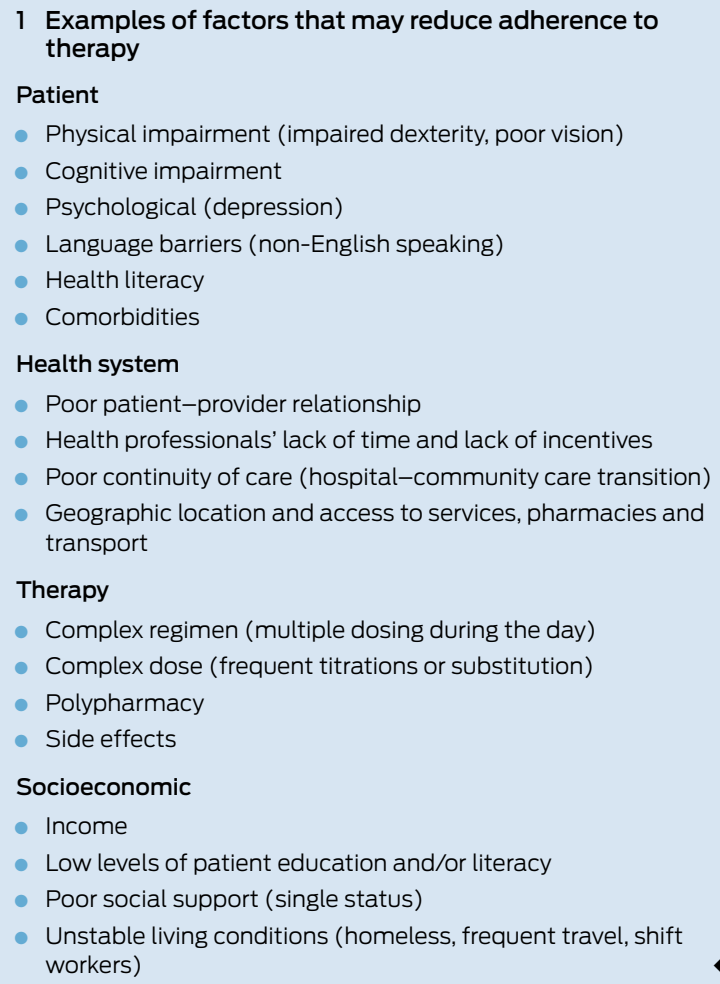

the occurrence and timing of bottle opening. However, even this cannot assess whether the patient actually takes the drug once the bottle is opened. While there is potential bias associated with misreporting and self-report, standardised questionnaires remain important tools to quantify non-adherence (Box 2). ${ }^{25,26}$

\section{Interventions to improve medical adherence}

Several interventions that target the modifiable factors that influence adherence have been explored (Box 3). Systematic reviews have examined improving medical adherence among chronic disease patients and identified a diverse range of interventions, including many that are complex. However, they have struggled with classifying interventions and thus pooling them to enable a comparison of their efficacy. ${ }^{27}$

There is very little research that directly trials interventions that improve medical adherence to secondary prevention drugs among patients with coronary heart disease. Secondary prevention programs, including cardiac rehabilitation programs, often include modules that focus on supporting lifestyle modification, risk factor management and medical adherence. ${ }^{28,29}$ The intensity of these programs ranges from face-to-face involvement in inhospital programs and telephone counselling ${ }^{30}$ to more recently - text message reminder systems. ${ }^{31}$ With regards to specific drugs, there has been examination of interventions to improve adherence to lipid-lowering drugs and hypertension medications in broader populations. ${ }^{32}$ The more recent of these, with respect to lipidlowering drugs, identified 11 studies and concluded that patient re-enforcement and reminding was the most promising category of interventions - it was investigated

\begin{tabular}{|c|c|c|}
\hline Questionnaire & Components & Features \\
\hline $\mathrm{BMQ}^{22}$ & $\begin{array}{l}\text { Three sets of questions: } \\
\text { - Five-item "regimen screen" } \\
\text { Two-item "recall screen" } \\
\text { Two-item "belief screen" }\end{array}$ & $\begin{array}{l}\text { Validated against } \\
\text { MEMS }\end{array}$ \\
\hline MARS-523 & $\begin{array}{l}\text { Modified from MARS-10 } \\
\text { Five-point Likert scale } \\
\text { First question: unintentional non-adherence } \\
\text { Other four statements: intentional non-adherence }\end{array}$ & $\begin{array}{l}\text { Variable sensitivity } \\
\text { reported in studies } \\
\text { (when matched with } \\
\text { pharmacy refill data) }\end{array}$ \\
\hline MMAS $^{24}$ & $\begin{array}{l}\text { Two versions: } \\
\text { MMAS-4 (original) } \\
\text { MMAS-8 (2008 modification) }\end{array}$ & $\begin{array}{l}\text { Brief; ease of } \\
\text { dichotomous response }\end{array}$ \\
\hline
\end{tabular}

$\mathrm{BMQ}=$ Brief Medication Questionnaire. MARS = Medication Adherence Rating Scale. MMAS = Morisky Medication Adherence Scale. MEMS = Medication Event Monitoring System.

\begin{tabular}{ll}
$\begin{array}{l}3 \\
\text { Modifiable factors influencing adherence and persistence and examples of } \\
\text { interventions }\end{array}$ \\
Modifiable factor & Intervention \\
\hline Regimen complexity & Simpler, less frequent dosing regimen \\
\hline Cost of therapy & Prescription of generic medications \\
\hline Pill burden & Combination polypill \\
\hline Improved tolerability & Selection of medication with low side-effect profile \\
\hline Patient acceptance of disease & Health literacy and counselling \\
\hline Patient trust in therapy & Patient-prescriber-pharmacist relationship \\
\hline Forgetfulness & Reminders \\
\hline
\end{tabular}

in six trials, of which four showed improved adherence, with an absolute increase in adherence ranging from $6 \%$ to $24 \% .{ }^{32}$

Another type of intervention that has been explored more recently involves simplifying the regimen by using fixed-dose combination medication. The UMPIRE study examined the impact of a fixed-dose combination (a fourdrug combination of aspirin, ACE inhibitor, statin, and either a $\beta$-blocker or a thiazide) in 2000 patients. The self-reported adherence in the intervention arm (polypill) at median 15-month follow-up was significantly higher (86\% v 65\%; relative risk of being adherent, 1.33 ; $95 \%$ CI, $1.26-1.41 ; P<0.001)$. The effect size was most marked among patients with poor baseline adherence. ${ }^{33}$

\section{What can a physician do?}

While there is increasing research interest in drug adherence, comprehensive data are not yet available. There is little literature on the comparative efficacy of interventions and, as such, there is no clear best way of achieving improved medical adherence. Also, it is unlikely that there will be a "one-size-fits-all" solution for all patients. ${ }^{34}$

From a practical viewpoint, some suggested approaches are described here. Screening for medical adherence can be done simply and should be done at every patient consultation. The most practical approach is to have a high index of suspicion, and to interview patients in a nonjudgemental manner. The discussion can be initiated with a neutral question, for example: 


\section{Questions to ask patients to assess their adherence to medicines ${ }^{35}$}

To assess medicine-taking behaviour

- How are you going with those tablets?

- How have you been taking these medicines?

To assess beliefs and attitudes

- How do you feel about taking these medicines?

- Have you ever thought about changing your medicines?

- How well does this medicine work for you?

To assess both

- It must be hard trying to remember to take the tablets every time. Do you ever forget? How do you feel about that?

- People often have difficulty taking their pills, and I am interested in finding out any problems that occur so that I can understand them better. Do you ever miss taking your medicines? How often?

- When you feel better, do you sometimes stop taking your medicine?

\section{SIMPLE approach to enhance adherence ${ }^{36}$}

S Simplify the regimen

I Impart knowledge

M $\begin{aligned} & \text { Modify patient } \\ & \text { beliefs and human } \\ & \text { behaviour }\end{aligned}$
behaviour

P Provide communication and trust L Leave bias

Adjust timing, frequency and number of tablets to suit patient

Attempt to change the situation, not the patient

Encourage use of adherence aids (eg, mobile app reminders)

- Focus on patient-provider shared decision making

- Provide written and verbal instructions

- Simple language and 3-4 major points

- Encourage involvement of nurse and pharmacist

\section{Empower patient to self-manage the condition}

Ensure patient understands the risk of not taking the medication

Address fears and concerns of patient

- Clear communication from provider

- Build safe environment where patient feels comfortable

- Informed and shared decision making

- Self-learning exercise in area and incorporating into practice

- Use of culturally and linguistically appropriate interventions

Tailor education to patient's level of understanding

E Evaluate adherence - Periodic review

- Self-report and medication adherence scales

- Biochemical tests - definitive confirmation

- "What do you think about taking these medications daily?"

- "How often do you miss taking them?"

Patients should also be asked about the cost of therapy and its affordability. It may also be important to ask about missed doses over longer periods (eg, the past month), to avoid the potential for "white-coat adherence" - a transient improvement in adherence for a few days before and after health personnel contact. A potential approach to questioning patients on adherence from the National Heart Foundation is summarised in Box 4. The American College of Preventive Medicine has also identified an approach that can be categorised under the mnemonic SIMPLE (Box 5). ${ }^{36}$

\section{Conclusion}

Non-adherence is a serious problem and a particularly important issue for patients with chronic disease requiring multiple medications. Low adherence is associated with increasing morbidity, mortality and increased costs of health care. Already, several innovative and effective strategies exist to improve adherence. Our standard of care needs to include identifying whether non-adherence exists, what individual factors are influencing it and what interventions may minimise non-adherence.

Acknowledgements: Clara Chow is supported by a National Health and Medical Research Council of Australia Career Development Fellowship (APP1033478) co-funded by the Heart Foundation and a Sydney Medical School Foundation Chapman Fellowship.

Competing interests: No relevant disclosures.

Provenance: Commissioned; externally peer reviewed.

1 Pearson TA, Blair SN, Daniels SR, et al. AHA Guidelines for primary prevention of cardiovascular disease and stroke: 2002 update: consensus panel guide to comprehensive risk reduction for adult patients without coronary or other atherosclerotic vascular diseases. American Heart Association Science Advisory and Coordinating Committee. Circulation 2002; 106: 388-391

2 Smith SC Jr, Allen J, Blair SN, et al. AHA/ACC guidelines for secondary prevention for patients with coronary and other atherosclerotic vascular disease: 2006 update: endorsed by the National Heart, Lung, and Blood Institute. Circulation 2006; 113: 2363-2372.

3 Chew DP, Anderson FA, Avezum A, et al. Six-month survival benefits associated with clinical guideline recommendations in acute coronary syndromes. Heart 2010; 96: 1201-1206.

4 Huynh LT, Chew DP, Sladek RM, et al. Unperceived treatment gaps in acute coronary syndromes. Int J Clin Pract 2009; 63: 1456-1464.

5 Heeley EL, Peiris DP, Patel AA, et al. Cardiovascular risk perception and evidence-practice gaps in Australian general practice (the AusHEART study). Med J Aust 2010; 192: 254-259.

6 Yusuf S, Islam S, Chow CK, et al. Use of secondary prevention drugs for cardiovascular disease in the community in high-income, middle-income, and low-income countries (the PURE Study): a prospective epidemiological survey. Lancet 2011; 378: 1231-1243.

7 Chow CK, Jolly S, Rao-Melacini P, et al. Association of diet, exercise, and smoking modification with risk of early cardiovascular events after acute coronary syndromes. Circulation 2010; 121: 750-758.

8 World Health Organization. Adherence to long-term therapies - evidence for action. Geneva: WHO, 2003. http://apps.who.int/medicinedocs/en/d/ Js4883e/6.html (accessed Oct 2014).

9 Ho PM, Bryson CL, Rumsfeld JS. Medication adherence: its importance in cardiovascular outcomes. Circulation 2009; 119: 3028-3035.

10 Osterberg L, Blaschke T. Adherence to medication. N Engl J Med 2005; 353 : 487-497.

11 Alm-Roijer C, Stagmo M, Udén G, Erhardt L. Better knowledge improves adherence to lifestyle changes and medication in patients with coronary heart disease. Eur J Cardiovasc Nurs 2004; 3: 321-330.

12 McCartney M. The patient paradox: why sexed-up medicine is bad for your health. London: Pinter \& Martin, 2012.

13 Britton A, McKee M, Black N, et al. Threats to applicability of randomised trials: exclusions and selective participation. J Health Serv Res Policy 1999; 4: $112-121$.

14 Bieszk N, Patel R, Heaberlin A, et al. Detection of medication nonadherence through review of pharmacy claims data. Am J Health Syst Pharm 2003; 60: 360-366.

15 Blackburn DF, Dobson RT, Blackburn JL, et al. Adherence to statins, betablockers and angiotensin-converting enzyme inhibitors following a first cardiovascular event: a retrospective cohort study. Can J Cardiol 2005; 21: 485-488.

16 Ho PM, Spertus JA, Masoudi FA, et al. Impact of medication therapy discontinuation on mortality after myocardial infarction. Arch Intern Med 2006; 166: 1842-1847.

17 Rasmussen JN, Chong A, Alter DA. Relationship between adherence to evidence-based pharmacotherapy and long-term mortality after acute myocardial infarction. JAMA 2007; 297: 177-186.

18 Spertus JA, Kettelkamp R, Vance C, et al. Prevalence, predictors, and outcomes of premature discontinuation of thienopyridine therapy after drug-eluting stent placement: results from the PREMIER registry. Circulation 2006; 113: 2803-2809.

19 Ho PM, Magid DJ, Shetterly SM, et al. Medication nonadherence is associated with a broad range of adverse outcomes in patients with coronary artery disease. Am Heart J 2008; 155: 772-779.

20 Peterson ED, Roe MT, Mulgund J, et al. Association between hospital process performance and outcomes among patients with acute coronary syndromes. JAMA 2006; 295: 1912-1920.

21 Influence of adherence to treatment and response of cholesterol on mortality in the coronary drug project. N Engl J Med 1980; 303: 1038-1041. 


\section{Modern challenges in acute coronary syndrome}

22 Svarstad BL, Chewning BA, Sleath BL, Claesson C. The Brief Medication Questionnaire: a tool for screening patient adherence and barriers to adherence. Patient Educ Couns 1999; 37: 113-124.

23 Thompson K, Kulkarni J, Sergejew AA. Reliability and validity of a new Medication Adherence Rating Scale (MARS) for the psychoses. Schizophr Res 2000; 42: 241-247.

24 Morisky DE, Ang A, Krousel-Wood M, Ward HJ. Predictive validity of a medication adherence measure in an outpatient setting. J Clin Hypertens (Greenwich) 2008; 10: 348-354.

25 Nguyen TM, Caze AL, Cottrell N. What are validated self-report adherence scales really measuring?: a systematic review. Br J Clin Pharmacol 2014; 77: 427-445.

26 Farmer KC. Methods for measuring and monitoring medication regimen adherence in clinical trials and clinical practice. Clin Ther 1999; 21: 10741090; discussion 1073.

27 Haynes RB, McDonald H, Garg AX, Montague P. Interventions for helping patients to follow prescriptions for medications. Cochrane Database Syst Rev 2002; (2): CD000011.

28 Balady GJ, Williams MA, Ades PA, et al. Core components of cardiac rehabilitation/secondary prevention programs: 2007 update: a scientific statement from the American Heart Association Exercise, Cardiac Rehabilitation, and Prevention Committee, the Council on Clinical Cardiology; the Councils on Cardiovascular Nursing, Epidemiology and Prevention, and Nutrition, Physical Activity, and Metabolism; and the American Association of Cardiovascular and Pulmonary Rehabilitation. J Cardiopulm Rehabil Prev 2007; 27: 121-129.

29 Wenger NK. Current status of cardiac rehabilitation. J Am Coll Cardiol 2008; 51: 1619-1631.
30 Cutrona SL, Choudhry NK, Fischer MA, et al. Modes of delivery for interventions to improve cardiovascular medication adherence. Am J Manag Care 2010; 16: 929-942.

31 Chow CK, Redfern J, Thiagalingam A, et al. Design and rationale of the tobacco, exercise and diet messages (TEXT ME) trial of a text messagebased intervention for ongoing prevention of cardiovascular disease in people with coronary disease: a randomised controlled trial protocol. BMJ Open 2012; 2: e000606.

32 Schedlbaver A, Davies P, Fahey T. Interventions to improve adherence to lipid lowering medication. Cochrane Database Syst Rev 2010; (3): CD004371.

33 Thom S, Poulter N, Field J, et al. Effects of a fixed-dose combination strategy on adherence and risk factors in patients with or at high risk of CVD: the UMPIRE randomized clinical trial. JAMA 2013; 310: 918-929.

34 United States Department of Health and Human Services Agency for Healthcare Research and Quality. Closing the Quality Gap series: medication adherence interventions: comparative effectivness. Executive summary. 2012. http://effectivehealthcare.ahrq.gov/index.cfm/searchfor-guides-reviews-and-reports/?productid=1249\&pageaction=displaypr oduct (accessed Sep 2014).

35 National Heart Foundation. Improving adherence in cardiovascular care. Module 2: Identifying patients' non-adherence. 2011. http://www. heartfoundation.org.au/SiteCollectionDocuments/QUM-Improvingadherence-Module-2.pdf (accessed Sep 2014).

36 American College of Preventive Medicine. Medication Adherence Time Tool: improving health outcomes. A resource from the American College of Preventive Medicine. 2011. http://www.acpm.org/?MedAdherTT_ ClinRef (accessed Sep 2014). 